\title{
VERMICOMPOSTEIRA EM ESCOLAS COMO ALTERNATIVA DE TRATAMENTO DE RESÍDUOS SÓLIDOS ORGÂNICOS E FERRAMENTA DE EDUCAÇÃO AMBIENTAL
}

\author{
Evandro De Freitas ${ }^{1}$ \\ Ramiro Pereira Bisognin ${ }^{2}$ \\ Robson Evaldo Gehlen Bohrer ${ }^{3}$ \\ Raquel Schmatz ${ }^{4}$ \\ Bruno Chaves ${ }^{5}$ \\ Marciel Redin 6
}

\begin{abstract}
RESUMO
A elevada produção de resíduos sólidos orgânicos no Brasil aliada a falta de coleta e destino adequado podem resultar em problemas ambientais, neste cenário, alternativas de baixo custo e fácil implantação se mostram importantes, como por exemplo, a vermicompostagem. O objetivo do presente estudo foi compreender o efeito da vermicompostagem no tratamento de resíduos sólidos orgânicos alimentares, e caracterizar a composição química do vermicomposto e chorume oriundos de uma escola municipal na cidade de Três Passos, RS. O vermicomposto e o chorume foram analisados quimicamente após 90 dias da implantação da vermicompostagem. Dentre as análises químicas realizadas, o processo de vermicompostagem afetou o $\mathrm{pH}$ em água e a relação $\mathrm{C} / \mathrm{N}$ dos resíduos orgânicos ao final de 90 dias. Após a estabilização do vermicomposto, $\mathrm{o} \mathrm{pH}$ em água foi de 8,2 e relação $\mathrm{C} / \mathrm{N}$ de 13,2, já o pH do chorume foi de 3,78 e 4,6 na $\mathrm{C} / \mathrm{N}$ solúvel. Com base nos resultados obtidos, a vermicompostagem se mostra como uma alternativa ambiental viável, que alia a disposição adequada de resíduos sólidos orgânicos e ao possível aproveitamento agrícola, tanto do vermicomposto quanto do biofertilizante para culturas. Este estudo possibilitou a geração de dados científicos integrados as práticas de sensibilização ambiental com 0 envolvimento de estudantes na montagem e operação de uma vermicomposteira.
\end{abstract}

Palavras-Chave: Restos de alimentos; Tratamentos de resíduos; Biofertilizante.

\footnotetext{
${ }^{1}$ Companhia Riograndense de Saneamento - Corsan/RS

2 Universidade Estadual do Rio Grande do Sul - UERGS

${ }^{3}$ Universidade Estadual do Rio Grande do Sul - UERGS

${ }^{4}$ Universidade Federal de Santa Maria - UFSM

${ }^{5}$ Universidade Federal de Santa Maria - UFSM

${ }^{6}$ Universidade Estadual do Rio Grande do Sul - UERGS
} 


\title{
VERMICOMPOSTEIRA IN SCHOOLS AS AN ALTERNATIVE FOR THE TREATMENT OF ORGANIC SOLID WASTE AND ENVIRONMENTAL EDUCATION TOOL
}

\begin{abstract}
The high production of organic solid wastes in Brazil together with the lack of adequate collection and destination can result in environmental problems, in this scenario, alternatives of low cost and easy implantation are important, such as vermicomposting. The objective of the present study was to understand the effect of vermicomposting on the treatment of solid organic food residues and characterize the chemical composition of vermicompost and slurry from a municipal school in the city of Três Passos, RS. The vermicompost and manure were analyzed chemically after 90 days of vermicomposting. Among the chemical analyzes performed, the vermicompost process affected the $\mathrm{pH}$ in water and the $\mathrm{C} / \mathrm{N}$ ratio of the organic residues at the end of 90 days. After stabilizing the vermicompost, the $\mathrm{pH}$ in water was 8.2 and the $\mathrm{C} / \mathrm{N}$ ratio was 13.2, and the $\mathrm{pH}$ of the manure was 3.78 and 4.6 in $\mathrm{C} / \mathrm{N}$ soluble. Based on the results obtained, the vermicomposting is shown as a viable environmental alternative, which combines the adequate disposal of organic solid waste and the possible agricultural use of both vermicompost and biofertilizer for crops. This study allowed the generation of integrated scientific data on environmental awareness practices with the involvement of students in the assembly and operation of a vermicomposter.
\end{abstract}

Keywords: Food residues; Waste treatment; Biofertilizer.

\section{INTRODUÇÃO}

A quantidade de resíduos sólidos gerados em 2016 pelos brasileiros foi de 78,3 milhões de toneladas, sendo que $91 \%$ deste total foram recolhidos pela rede de coleta dos municípios, contudo, apenas 41,7 milhões de toneladas tiveram uma disposição final ambientalmente adequada. Dentre os resíduos sólidos gerados, há uma grande quantidade de resíduos orgânicos, porém, o aproveitamento destes materiais ainda é muito baixo, principalmente pelo fato de estar misturado a resíduos inorgânicos, como consequência da precariedade da separação e coleta seletiva no Brasil (ABRELPE, 2016). Uma alternativa para mudar este cenário envolve o comprometimento do poder público, da sociedade e dos próprios consórcios de coleta para a promoção dos destinos corretos dos resíduos.

O tratamento dos resíduos orgânicos pode ser realizado através da compostagem, resultando em um composto humificado com potencial de 
utilização na agricultura (JUNIOR et al., 2005). Um método alternativo para este tratamento de resíduos sólidos orgânicos é a vermicompostagem, processo que inclui minhocas à técnica de compostagem de forma a transformar os materiais de origem orgânica em composto estabilizado (AQUINO et al., 1992). Dentre as espécies de minhocas mais utilizadas na vermicompostagem, as californianas (Eisenia foetida) ou as africanas (Eudrilus eugeniae) se destacam, pois são amplamente comercializadas, tolerantes à variação de temperatura, adaptadas a diversos tipos de resíduos e ainda apresentam grande capacidade de transformação de materiais orgânicos (DOMÍNGUEZ; EDWARDS, 2004; AQUINO et al., 2005). Uma característica comum da vermicompostagem é a diminuição do volume do material orgânico, causado principalmente pela decomposição dos materiais orgânicos e evaporação de água (ANDREOLI, 2001).

A preservação ambiental está ligada a ações sustentáveis e, nesse sentido, para contribuir com a educação ambiental, valorizar a utilização de Resíduos Sólidos Orgânicos (RSO) e gerar economia de recursos aos cofres públicos, tem-se como alternativa de tratamento as vermicomposteiras, principalmente para cascas e restos de frutas, legumes e verduras (BRASIL, 2010). Ainda, a Política Nacional de Resíduos Sólidos (PNRS) define que somente poderão ser depositados em aterros, resíduos sem qualquer possibilidade de reciclagem e reaproveitamento, indicando a compostagem aos resíduos sólidos orgânicos (BRASIL, 2010).

O Consórcio Intermunicipal de Gestão Multifuncional (CITEGEM), situado no Noroeste do Rio Grande do Sul, região de realização deste estudo, registra o recebimento de elevados percentuais resíduos sólidos orgânicos, principalmente dos maiores municípios que compõem o consórcio, como Três Passos (CITEGEM, 2018). Este município destinou ao aterro sanitário, no segundo semestre de 2017, 1.807,09 toneladas de resíduos, sendo 36,67\% resíduos secos e 63,33\% orgânicos. Somente nos primeiros meses de 2018, de janeiro a março, o mesmo município há havia enviado ao consórcio 1.021,24 toneladas de resíduos, sendo 34,94\% seco e 65,06\% orgânico (CITEGEM, 2018). Estes dados denotam a necessidade de ações para minimizar o volume de resíduos orgânicos destinados aos aterros sanitários. Nesse sentido, para aumentar o percentual de reciclagem e compostagem de 
resíduos orgânicos, é importante o uso de ferramentas como a educação ambiental nas escolas, pois ela propicia o aumento de conhecimentos, mudança de valores, aperfeiçoamento de habilidades que materializam as condições básicas para que o ser humano assuma atitudes e comportamentos frente ao meio ambiente. O estudo realizado por Rodrigues e Dantas (2018), em escola do semiárido nordestino, identificou que a maioria (64\%) dos 90 estudantes contemplados na pesquisa vê o lixo como algo inútil, sendo que $69 \%$ dos alunos informaram abordar o tema somente nas aulas de biologia. No entanto, os próprios alunos reconheceram que os projetos e as ações de sensibilização são os meios mais prováveis de se minimizar o volume de resíduos.

Ainda, o potencial agronômico do vermicomposto e do chorume biofertilizante é conhecido e pode ser utilizado na fertilização de plantas (FRANCELIN e CORTEZ, 2014). No entanto, ainda é pouco conhecido o volume de chorume gerado da vermicompostagem de resíduos domiciliares e escolares, bem como a sua composição química, os quais podem apresentar grande variação em função das propriedades iniciais dos RSO. Neste contexto, o presente trabalho apresenta, além de uma alternativa para economia de recursos financeiros, a possibilidade de produzir alimentos mais saudáveis com a utilização dos fertilizantes orgânicos, e a disposição ambientalmente adequada dos resíduos orgânicos, de forma integrada e participativa dos estudantes.

Assim, o objetivo do presente estudo foi compreender o efeito da vermicompostagem no tratamento de resíduos sólidos orgânicos alimentares, e caracterizar a composição química do vermicomposto e chorume oriundos de uma escola municipal na cidade de Três Passos, RS.

\section{MATERIAIS E MÉTODOS}

O presente trabalho foi realizado no período de novembro/2016 a janeiro/2017 na Escola Municipal de Ensino Fundamental 25 de Julho, em Três Passos, RS. A escola conta com 250 alunos e um quadro de funcionários composto por 22 profissionais. Ao todo, a quantidade de resíduos sólidos 
orgânicos gerados mensalmente, principalmente resíduos de alimentos, é de aproximadamente $250 \mathrm{~kg}$.

Antes da instalação da vermicomposteira, foram ministradas palestras para capacitação dos 180 alunos de ensino fundamental, 70 alunos do ensino médio, 15 professores e 7 funcionários, que ficaram responsáveis pela execução do projeto. Além disso, foram explicados os processos técnicos de vermicompostagem e geração de chorume, bem como a separação correta dos resíduos a serem utilizados. Os alunos, funcionários e professores também foram instruídos sobre o procedimento de montagem, funcionamento e manejo da vermicomposteira

A definição da capacidade da vermicomposteira instalada na escola foi definida por meio do levantamento da geração de resíduos orgânicos diários e estimou-se que para 90 dias de adição de RSO, com uma margem de $20 \%$ de segurança, seria necessário um reservatório de 500 L. A instalação da vermicomposteira ocorreu em local sombreado, sobre uma base feita de alvenaria com $50 \mathrm{~cm}$ de altura, declive interno de aproximadamente $1 \%$ para 0 escoamento do chorume a um reservatório instalado ao lado da vermicomposteira. O modelo proposto e utilizado consistiu-se de uma caixa de polietileno, além de tubos e conexões, tela alumínio $0,5 \mathrm{~mm}$ e reservatório para coleta do chorume gerado da vermicompostagem (Figura 1).

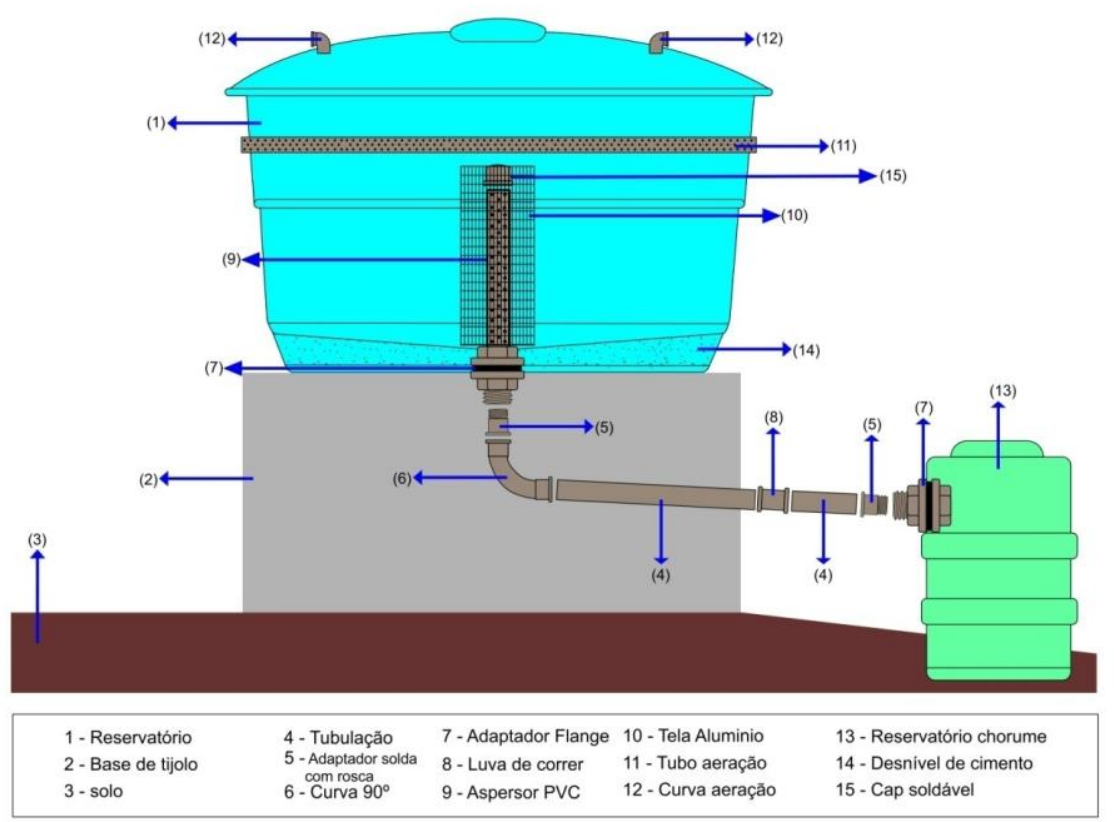

Figura 1 - Esquema ilustrativo da vermicomposteira com o dispositivo para a coleta do chorume. Autoria própria. 
No interior do reservatório foi necessário criar um declive das laterais ao centro feito com areia e cimento para que o chorume pudesse escoar por gravidade. No centro foi instalado o aspersor, um tubo plástico do mesmo diâmetro do flange com vários orifícios de $3 \mathrm{~mm}$. Para recobrir o aspersor foi colocado o cap soldável na extremidade da tubulação, sendo este fixado no flange localizado na parte interna do reservatório, que através dele foi coletado o chorume gerado na vermicompostagem, seguindo para o reservatório plástico de 20 litros.

Após a pesagem, os RSO como cascas de frutas, legumes e restos de verduras eram dispostos na vermicomposteira junto com as minhocas californianas da espécie $E$. foetida, na proporção de $1 \mathrm{~kg}$ de minhocas por $\mathrm{m}^{3}$ de RSO. As adições acorreram durante os primeiros 60 dias, diariamente ou intercaladas conforme as gerações dos resíduos orgânicos e chegou a $166 \mathrm{~kg}$ de RSO dispostos na vermicomposteira e cobertos levemente com aproximadamente $1 \mathrm{~cm}$ de serragem seca grossa.

Dentre os parâmetros de monitoramento, a temperatura do composto e do ar foi medida toda vez que eram adicionados resíduos na vermicomposteira, com termômetro tipo espeto. A umidade foi controlada ao longo do processo, da mesma forma que a temperatura, durante a adição de RSO, a qual se manteve em torno de $85 \%$, tendo sido necessária sua correção com recirculação do chorume somente depois do fim das adições diárias de resíduos. Não houve revolvimento dos resíduos, uma vez que um dos objetivos do trabalho foi também avaliar a eficiência do sistema de aeração adotado, para propiciar maior facilidade no manejo. Para a aeração foram feitas perfurações de várias linhas ao redor do reservatório, acima da camada de húmus, com furos de $3 \mathrm{~mm}$ a uma distância de 5 a $8 \mathrm{~cm}$ entre linhas e furos de modo a facilitar a entrada de oxigênio, manter a temperatura dentro da faixa ideal, além de impedir a entrada de moscas para o interior da vermicomposteira.

Nos RSO utilizados na vermicompostagem foram realizadas as análises de carbono e nitrogênio totais pelo método de combustão seca. Após 90 dias do início da compostagem, foram realizadas análises físico-químicas no composto orgânico tais como: pH em água, índice SMP, Fósforo, Potássio, Cálcio, 
Magnésio, CTC, H + Al, Enxofre, Zinco, Cobre, Boro, Manganês, Carbono e Nitrogênio. No chorume, foram avaliados: Carbono, Nitrogênio, Nitrato/nitrito, Amônia, Fósforo, Potássio, Cálcio, Magnésio, pH e porcentagem de matéria seca, conforme o uso de metodologias descritas em Tedesco et al, (1995). Os dados obtidos foram descritos através de análises descritivas, gráficas ou tabelas para a melhor visualização dos resultados. Por fim, realizou-se uma abordagem econômica de recursos financeiros ao município com a possibilidade de implantação de vermicomposteiras domiciliares.

\section{RESULTADOS E DISCUSSÕES}

Após 90 dias da última adição, a massa do vermicomposto foi de $31 \mathrm{~kg}$, representando uma diminuição de $81,4 \%$ da massa inicial de resíduos $(166 \mathrm{~kg})$, evidenciando, de acordo com relatado por Andreoli (2001), a diminuição de massa do material orgânico, pela decomposição e perda de umidade, durante a vermicompostagem. Além disso, a quantidade de chorume gerada ao longo deste período foi de 46 litros. A temperatura do ar e do composto durante 0 período de adição de RSO no experimento apresentou variação a ser observada na Figura 2.

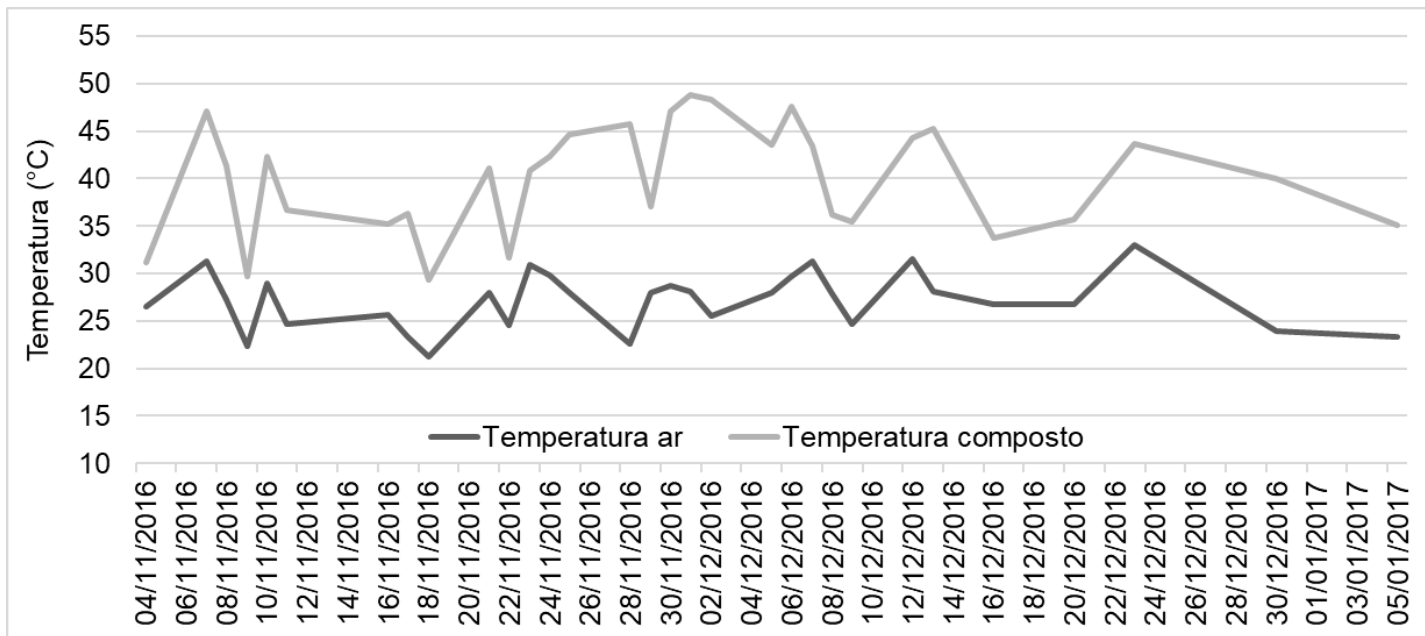

Figura 2 - Temperatura do ar e do composto durante os 60 dias iniciais do processo da vermicompostagem.

Pode-se observar que a temperatura média na vermicomposteira foi de $40,1^{\circ} \mathrm{C}$, um pouco acima do recomendado para um processo de 
vermicompostagem (KIEHL, 2004), devido à ação dos microrganismos na decomposição do material orgânico, associado à estação quente, ou seja, meses de novembro, dezembro e janeiro. Embora valores elevados de temperatura dentro da vermicomposteira impulsionem a decomposição dos resíduos orgânicos pelos microrganismos termofílicos, temperaturas acima de $35^{\circ} \mathrm{C}$ podem ocasionar a morte das minhocas (VERAS e POVINELLI, 2004). No entanto, Sharma et al. (1997) relatam que a vermicompostagem pode ser feita em ambientes em que a temperatura alcance até $40^{\circ} \mathrm{C}$. Foi observado que a quantidade inicial de minhocas adicionadas à vermicomposteira aproximadamente triplicou após os 90 dias.

As análises químicas realizadas no vermicomposto ao final do processo da vermicompostagem são apresentadas na Tabela 1.

Tabela 1 - Composição química do vermicomposto após a estabilização, aos 90 dias.

\begin{tabular}{cc}
\hline Composição & Valor \\
\hline pH em água & 8,2 \\
Fósforo $(\mathrm{mg} / \mathrm{kg})$ & 700 \\
Potássio $(\mathrm{mg} / \mathrm{kg})$ & 1468 \\
Cálcio $(\mathrm{cmolc} / \mathrm{L})$ & 7,8 \\
Magnésio $(\mathrm{cmolc} / \mathrm{L})$ & 6,8 \\
CTC $(\mathrm{cmolc} / \mathrm{L})$ & 53,3 \\
Matéria orgânica $(\%)$ & 13,2 \\
$\mathrm{H}+$ Al $(\mathrm{cmolc} / \mathrm{L})$ & 1,1 \\
Enxofre $(\mathrm{mg} / \mathrm{kg})$ & 198,7 \\
Zinco $(\mathrm{mg} / \mathrm{kg})$ & 21,4 \\
Cobre $(\mathrm{mg} / \mathrm{kg})$ & 0,5 \\
Boro $(\mathrm{mg} / \mathrm{kg})$ & 2,8 \\
Manganês $(\mathrm{mg} / \mathrm{kg})$ & 5 \\
Nitrogênio $(\%)$ & 1,9 \\
Carbono $(\%)$ & 25,1 \\
Umidade $(\%)$ & 84,7 \\
\hline
\end{tabular}


$\mathrm{O}$ pH em água do vermicomposto após sua estabilização foi levemente alcalino $(8,2)$, sendo que na literatura o intervalo do $\mathrm{pH}$ em água indicado para aplicação na agricultura deve estar entre 6 e 8,5 (Sharma et al. 1997) portanto, ao final do processo de estabilização o pH encontrava-se na faixa indicada. $\mathrm{A}$ relação $\mathrm{C} / \mathrm{N}$ do RSO do início foi de 32,4, e no vermicomposto, após 90 dias do processo, foi de 13,2 indo de encontro com as informações encontradas na literatura para compostos deste tipo, já estabilizados, conforme o intervalo de 10 a 20 recomendado por Fernandes e Silva (1999). A relação $\mathrm{C} / \mathrm{N}$ influencia diretamente na velocidade dos microrganismos quanto à degradação do material orgânico, uma vez que o carbono é responsável pela sua fonte de energia e o nitrogênio por seu crescimento e reprodução. Ainda, Fernandes e Silva (1999) recomendam que a relação $\mathrm{C} / \mathrm{N}$ no início do processo de compostagem-vermicompostagem pode variar de 30 a 70 . Os resultados obtidos para a relação $\mathrm{C} / \mathrm{N}$ final no presente estudo $(13,2)$, indicam que 0 processo da vermicompostagem foi eficiente no tratamento dos RSO e também como um parâmetro de avaliação da estabilização do vermicomposto.

Os valores de macronutrientes do vermicomposto são similares ou maiores, quando comparados, por exemplo, aos encontrados nos resíduos de espécies agrícolas, o que pode ser um importante fertilizante para utilização na agricultura ou nas hortas domiciliares. Por exemplo, Redin et al. (2014) em estudo com resíduos culturais da parte aérea de 25 espécies observaram, em média, $1,7 \%$ de nitrogênio na matéria seca, similar ao encontrado no vermicomposto do presente estudo. Os valores de fósforo e potássio no vermicomposto são aproximadamente o dobro daqueles encontrados no estudo de Giacomini et al. (2003), nos resíduos culturais de aveia preta, ervilhaca e nabo forrageiro. Os macronutrientes são extremamente importantes para o desenvolvimento das plantas. Segundo Souza e Lobato (2004), o nitrogênio é responsável pela formação de proteínas, o fósforo age na respiração e produção de energia, e o potássio é indispensável para a produção de energia das plantas. O cálcio, além de estimular a absorção de íns, é responsável por garantir o funcionamento das membranas celulares das plantas, influenciando ainda no $\mathrm{pH}$ desta. O magnésio, por sua vez, quando não está presente no solo pode levar à inibição da floração, redução do 
crescimento e degeneração dos frutos. Já o enxofre auxilia na defesa contra pragas e melhora a qualidade nutritiva dos alimentos.

Com o propósito de verificar as características do chorume gerado na vermicompostagem, também foram feitas análises físico-químicas, que estão expressas na Tabela 2. $\mathrm{O} \mathrm{pH}$ do chorume resultante do processo de vermicompostagem no presente estudo foi de 3,78, devendo ser corrigido antes de ser aplicado na agricultura, de forma a evitar acidez do solo e também danos diretos às plantas. Essa afirmação é baseada no Manual de Recomendação de Adubação e Calagem dos Estados do RS e SC (CQFS, 2016), que estabelece $\mathrm{pH}$ do solo entre 5,5 e 6,5 para a maioria das culturas. $\mathrm{O}$ resultado de $\mathrm{pH}$ no presente estudo é menor se comparado aqueles obtidos por Silva et al. (2007), que compararam a composição química de dois biofertilizantes elaborados pela Embrapa. $\mathrm{O} \mathrm{pH}$ relativamente baixo do chorume pode estar associado a natureza do material inicial da vermicompostagem de natureza ácido, como por exemplo, os resíduos de alimentos, especialmente, as saladas temperadas com vinagre.

Tabela 2 - Análises físico-químicas do chorume oriundo da vermicompostagem.

\begin{tabular}{cc}
\hline Composição & Valor \\
\hline Carbono solúvel $(\mathrm{mg} / \mathrm{L})$ & 99,7 \\
Nitrogênio solúvel $(\mathrm{mg} / \mathrm{L})$ & 21,7 \\
Nitrato/nitrito $-\mathrm{NO}_{3} / \mathrm{NO}_{2}(\mathrm{mg} / \mathrm{L})$ & 0,4 \\
Amônia $-\mathrm{NH}_{3}(\mathrm{mg} / \mathrm{L})$ & 40,5 \\
Fósforo solúvel $(\mathrm{mg} / \mathrm{L})$ & 31,9 \\
Potássio solúvel $(\mathrm{mg} / \mathrm{L})$ & 1342 \\
Cálcio solúvel $(\mathrm{mg} / \mathrm{L})$ & 193 \\
Nitrogênio total $(\mathrm{mg} / \mathrm{L})$ & 375 \\
Fósforo total $(\mathrm{mg} / \mathrm{L})$ & 1,1 \\
Potássio total $(\mathrm{mg} / \mathrm{L})$ & 92,3 \\
Cálcio total $(\mathrm{mg} / \mathrm{L})$ & 2,5 \\
Magnésio total $(\mathrm{mg} / \mathrm{L})$ & 1,3 \\
$\quad$ pH & 3,8 \\
Matéria seca $(\%)$ & 1,7
\end{tabular}


O chorume apresentou elevados conteúdos de componentes solúveis em água e totais (fração orgânica e inorgânica), sobretudo os carbonados e nitrogenados (Tabela 2). Autores sugerem que o chorume proveniente de processos de compostagem de materiais orgânicos, livre de contaminantes, possui grande potencial de aplicabilidade na agricultura ou hortas domiciliares como biofertilizante, repelente e defensivo agrícola (por exemplo, FRANCELIN e CORTEZ, 2014). O chorume, quando utilizado na fertirrigação, contribui para a nutrição das plantas e para o controle de pragas, podendo possuir ainda efeito fito hormonal, bactericida, fungicida e nematicida (SILVA et al., 2007). No entanto, o alto conteúdo de componentes nitrogenados (nitrogênio solúvel e total), além do fósforo e potássio solúveis, e potássio total no chorume, quando aplicado ao solo sem a recomendação técnica (CQFS, 2016) e/ou em doses elevadas, podem ser lixiviados e causar poluição ambiental, como a eutrofização, ocasionada pelo enriquecimento das águas por nutrientes, como fósforo e nitrogênio, que elevam a produtividade primária e favorecem 0 florescimento de algas clorofíceas e cianofíceas que desequilibram os ecossistemas aquáticos (DODDS et al., 2009). Ainda em relação à composição do vermicomposto, o conteúdo elevado de zinco (Tabela 1) também pode provocar efeitos tóxicos no solo e plantas, pois está com nível acima do recomendado (CQFS, 2016). O excesso de zinco na planta, pode afetar negativamente a fotossíntese pela inibição da biossíntese de clorofila e diminuição da assimilação de carbono (DHIR et al., 2008).

Fernandes e Silva (1999) sugerem que a utilização de compostos oriundos de processos de compostagem ou vermicompostagem possuem grande importância na manutenção de húmus estável para o solo, uma vez que este é constantemente perdido pelo processo de mineralização natural. Os mesmos autores ressaltam ainda que embora estes substratos produzidos através da degradação de resíduos orgânicos sirvam como um condicionador do solo, melhorando suas propriedades físicas, químicas e biológicas, este, quando aplicado à agricultura, deve estar aliado a fertilizantes minerais.

Estas informações foram essenciais para a compreensão dos estudantes sobre os possíveis danos ocasionados ao meio ambiente, especialmente contaminação do solo e das águas, quando não são adotadas medidas adequadas de gerenciamento de resíduos sólidos. Os alunos 
envolvidos também puderam compreender os processos biológicos que ocorrem naturalmente no ambiente e os benefícios e potencialidades da adubação orgânica para produção de alimentos mais saudáveis. Um estudo realizado por Gomes et al. (2018), com alunos do $6^{\circ}$ ao $9^{\circ}$ ano do ensino fundamental no município de Buriti dos Lopes/PI, verificou que os alunos se reconhecem como parte integrante do meio ambiente e como agentes transformadores desse meio. Nesse estudo, os autores observaram que as aulas diferenciadas proporcionaram maior facilidade para assimilação da temática e sua importância pelos alunos, assim como evidenciado no presente estudo, com o gerenciamento dos resíduos da escola, operação e monitoramento da vermicomposteira e do chorume. Da mesma forma, como relatado no estudo de Gomes et al. (2018), as atividades sensibilizaram os alunos a serem mais participativos nas ações de preservação e conservação do meio ambiente.

Por fim, diante dos resultados obtidos, destaca-se que estudos técnicos associados à educação ambiental são relevantes para geração de dados científicos, bem como para formação escolar consciente. Esta informação é corroborada por Menezes et al. (2018), os quais salientam que as práticas ambientais nas escolas são fundamentais para a consolidação de atitudes socioambientais, uma vez que a escola é promotora de conhecimento e cidadania, e deve atender aos anseios socioambientais de seus alunos.

\section{CONCLUSÕES}

O vermicomposto e o chorume apresentam uma quantidade significativa de nutrientes importantes para utilização no solo uma vez que suas propriedades químicas condizem com as recomendadas para o cultivo de plantas.

Com a implantação de vermicomposteiras nas escolas do município de Três Passos, presume-se que este método diminuiria os custos com o transporte e disposição final dos resíduos, além de gerar um subproduto aproveitável como condicionador e fertilizante de solo na agricultura ou mesmo para hortas escolares, proporcionando a sensibilização ambiental dos alunos desde as séries iniciais. 


\section{REFERÊNCIAS}

ABRELPE. Panorama dos Resíduos Sólidos no Brasil 2016. Associação Brasileira de Empresas de Limpeza Pública e Resíduos Especiais. Relatório Anual, 2016.

ANDREOLI, C. V. Resíduos sólidos do saneamento: processamento, reciclagem e disposição final. PROSAB, RIMA, ABES, Rio de Janeiro, 2001.

AQUINO, A. M.; ALMEIDA, D. L.; SILVA, V. F. Utilização de minhocas na estabilização de resíduos orgânicos: vermicompostagem. Embrapa, n. 8, p. 1-6, 1992.

AQUINO, A. M.; OLIVEIRA, A. M. G.; LOUREIRO, D. C. Integrando compostagem e vermicompostagem na reciclagem de resíduos orgânicos domésticos. Circular Técnica, Seropédica, RJ, 2005.

BRASIL. Lei 12.305, de 02 de agosto de 2010. Institui a Política Nacional de Resíduos Sólidos; altera a Lei no 9.605, de 12 de fevereiro de 1998; e dá outras providências. Disponível em: <http://www.planalto.gov.br/ccivil 03/ ato2007-2010/2010/lei/l12305.htm>. Acesso em: dez. 2018.

CITEGEM. Consórcio Intermunicipal de Gestão Multifuncional. Relatório de recebimento de resíduos. Disponível em: $<$ http://citegem.com.br/arq/publicacao/ygj9mb8su2fr.pdf> e < http://citegem.com.br/arq/publicacao/vlgspeud1ak0.pdf>. Acesso em: ago. 2018.

CQFS - COMISSÃO DE FERTILIDADE DO SOLO RS/SC. Manual de Calagem e Adubação para os Estados do Rio Grande do Sul e Santa Catarina. Porto Alegre: Núcleo Regional Sul, Sociedade Brasileira de Ciência do Solo, 2016. 376 p.

DHIR, B., SHARMILA, P., PARDHA S. P. Photosynthetic performance of Salvinia natans exposed to chromium and zinc rich wastewater. Brazilian Journal of Plant Physiology, v. 20, p. 61-70, 2008.

DODDS, W. K. et al. Eutrophication of U.S. freshwaters: analysis of potential economic damages. Environmental Science \& Technology, v.43, n.1, p. 1219, 2009.

DOMÍNGUEZ, J.; EDWARDS, C. A. Vermicomposting organic wastes: a review. Soil Zoology for Sustainable Development in the 21st Century, SH Shakir Hanna ans WZA Mikhail, Cairo, 2004.

FERNANDES, F.; SILVA, S. M. C. P. Manual prático para a compostagem de biossólidos. PROSAB, Londrina, 1999.

FRANCELIN, L. P.; CORTEZ, A. T. C. Compostagem: por uma escola mais sustentável. Ciência Geográfica, v. 18, p. 116-130, 2014. 
GIACOMINI, S. J. et al. Liberação de fósforo e potássio durante a decomposição de resíduos culturais em plantio direto. Pesquisa Agropecuária. Brasileira, vol. 38, n. 9, p. 1097-1104, 2003.

GOMES, J. N. D. et al. Educação ambiental na conscientização e preservação do meio ambiente: unidade escolar Zezita Sampaio, Butiti dos Lopes, PI. Revista de Educação Ambiental, v. 23, n. 1, p. 225-247, 2018.

JUNIOR, C. H. A. et al. Uso agrícola de resíduos orgânicos potencialmente poluentes: Propriedades químicas do solo e produção vegetal. Tópicos em ciência do solo, v. 4, p. 391-470, 2005.

KIEHL, E. J. Manual de compostagem: maturação e qualidade do composto. 4.ed. Piracicaba: Editora Degaspari, 173 p., 2004.

MENEZES, J. B. F. de et al. conceitos, práticas de educação ambiental e formação cidadã na escola. Revista de Educação Ambiental, v. 23, n. 1, p. 185-197, 2018.

REDIN M, et al. How the chemical composition and heterogeneity of crop residue mixtures decomposing at the soil surface affects $\mathrm{C}$ and $\mathrm{N}$ mineralization. Soil Biology and Biochemistry, v. 78, p. 65-75, 2014.

RODRIGUES, C. M. C.; DANTAS, M. C. A perspectiva discente sobre os resíduos sólidos em uma escola do semiárido nordestino. Revista de Educação Ambiental, v. 23, n. 1, 2018.

SHARMA, V. K.; CANDITELLI, M.; FORTUNA, F.; CORNACCHIA, G. Processing of urban and agro-industrial residues by aerobic composting: review. Energy Conversion and Management, v. 38, n. 5, p. 453-478, 1997.

SILVA, A. F. et al. Preparo e uso de biofertilizantes líquidos. Embrapa, Comunicado Técnico, Petrolina, 2007.

TEDESCO, M. J. et al. Análises de solo, plantas e outros materiais. Porto Alegre: Universidade Federal do Rio Grande do Sul, Departamento de Solos, 174 p., 1995. (Boletim Técnico, 5).

VERAS, L. R. V.; POVINELLI, J. A vermicompostagem do lodo de lagoas de tratamento de efluentes industriais consorciada com composto de lixo urbano. Engenharia Sanitária e Ambiental, v. 9, n. 3, p. 218-224, 2004. 